\title{
Interdisciplinary Differences in Patient Safety Culture within a Teaching Hospital in a South East Asia
}

\author{
Karthikayini Krishnasamy ${ }^{1}$, Maw Pin Tan ${ }^{2}$, and Mohd Idzwan Zakaria ${ }^{1}$ \\ ${ }^{1}$ Universiti Malaya \\ ${ }^{2}$ University of Malaya
}

November 19, 2020

\begin{abstract}
Background: Patient safety represents a global issue which leads to potentially avoidable morbidity and mortality. This study aimed to determine the inter-professional differences in patient safety culture in a tertiary university hospital. Method: A cross-sectional study using the Safety Attitude Questionnaire (SAQ) self-administered electronically in the English and Malay languages to evaluate safety culture domains. A positive percentage agreement score of $60 \%$ was considered satisfactory. Comparisons were made between clinicians, nurses, allied health professionals, ward attendants and support staff. Results: Of 6562 potential respondents, $5724(80.4 \%)$ completed the questionnaire; 3930 (74.5\%) women, $2263(42.9 \%)$ nurses, and 1812 (34.2\%) had 6-10 years of working experience. The mean overall positive percentage agreement scores were 66.2 (range=31.1 to $84.7 \%$ ), with job satisfaction $(72.3 \pm 21.9 \%)$ and stress recognition $(58.3 \pm 25.6 \%)$ representing the highest and lowest mean domain scores respectively. Discussion: Differences were observed between all five job categories. Linear regression analyses revealed that the other four job categories scored lower in teamwork, safety culture, job satisfaction, and working conditions compared to nurses. Conclusions: The overall mean SAQ score was above the satisfactory level, with unsatisfactory percentage agreement scores in the stress recognition domain. Interventions to improve patient safety culture should be developed, focusing on stress management.
\end{abstract}

$18^{\text {th }}$ November 2020

The Editor-in-Chief

Journal of Clinical Practice

Dear Editor,

Re: Interdisciplinary Differences in Patient Safety Culture within a Teaching Hospital in a South East Asia

We would be grateful if you will consider our manuscript entitled "Interdisciplinary Differences in Patient Safety Culture within a Teaching Hospital in a South East Asia" for publication in your journal. Few studies to date have evaluated patient safety culture in Asia. We conducted a survey involving over 5000 healthcare workers at a large teaching hospital in Malaysia and evaluated differences in responses between professional groups. Our findings found that overall agreement scores exceeded the satisfactory cut-off scores of $60 \%$ and so did all domain scores apart from stress awareness. There were significant differences, however, between professional groups, with nurses having superior scores in nearer all domains compared to doctors, allied health professionals and support workers.

We are certain that our novel findings would be of great interest to your readers, particularly to address the gap in international publications on patient safety.

Thank you. 
Yours sincerely,

Dr Maw Pin TAN

Professor

Department of Medicine

Faculty of Medicine

University of Malaya

Kuala Lumpur

mptan@ummc.edu.my; +60 163328600

\section{Hosted file}

Manuscript edited JCP.pdf available at https://authorea.com/users/377133/articles/493920interdisciplinary-differences-in-patient-safety-culture-within-a-teaching-hospital-in-asouth-east-asia

\section{Hosted file}

Table1 Characteristic of Respondents edited.pdf available at https://authorea.com/users/ 377133/articles/493920-interdisciplinary-differences-in-patient-safety-culture-within-ateaching-hospital-in-a-south-east-asia

\section{Hosted file}

Table 2 Percentage Agreement Scores by Job Category.pdf available at https://authorea.com/ users/377133/articles/493920-interdisciplinary-differences-in-patient-safety-culturewithin-a-teaching-hospital-in-a-south-east-asia

\section{Hosted file}

Figure 1 Levels of Positive Percentage Agreement.pdf available at https://authorea.com/users/ 377133/articles/493920-interdisciplinary-differences-in-patient-safety-culture-within-ateaching-hospital-in-a-south-east-asia

\section{Hosted file}

Table 3 Mean Difference in Domain Scores by Job Categories edited.pdf available https://authorea.com/users/377133/articles/493920-interdisciplinary-differences-inpatient-safety-culture-within-a-teaching-hospital-in-a-south-east-asia 